American J. of Engineering and Applied Sciences 2 (1): 39-43, 2009

ISSN 1941-7020

(C) 2009 Science Publications

\title{
Reduced Order Models of a Current Source Inverter Induction Motor Drive
}

\author{
Ibrahim K. Al-Abbas \\ Department of Mechatronics Engineering, \\ Faculty of Engineering Technology, Al-Balqa Applied University, Amman, Jordan
}

\begin{abstract}
Problem Statement: The current source inverter induction motor (CSI-IM) drive was widely used in various industries. The main disadvantage of this drive was nonlinearity and complexity. This work was done to develop a simple drive systems models. Approach: The MATLAB/SIMULINK software was used for system modeling. Three reduced models were developed by choosing specific frame, neglecting stator transients and ignoring stator equations. Results: The dynamic performance of the models was examined in open loop form for a step change in control variable (the input voltage) as well as for step change in disturbance (mechanical load).Conclusion: The three models were equivalent in steady state. The error of these models in the transient response was less than $5 \%$, with the exception of the time performances of the transient model to step change of supply voltage. Recommendations: All three models were suggested to be used for designing torque control systems. The detailed and stator equation models were recommended to be used in speed control design.
\end{abstract}

Key words: Current source inverter, induction motor, Reduced order modeling

\section{INTRODUCTION}

The advantages of ac motors in variable speed applications include lower initial cost compared to dc motors and less maintenance, because there are neither brushes nor replace, or commutator to resurface. Variable frequency Induction Motor (IM) drives are widely used in various industries. The IM is driven via a Voltage Source Inverter (VSI) or a Current Source Inverter (CSI). The current source inverter is more interactive with the load and therefore, a close match between the inverter and the machine is desirable. In addition to that, the CSI has an inherent four-quadrant operation capability and does not require any extra power components. Moreover, it is more rugged, reliable and simple to be controlled ${ }^{[1-4]}$.

The main disadvantages of the Current Source Inverter Induction Motor (CSI-IM) drive are sluggish

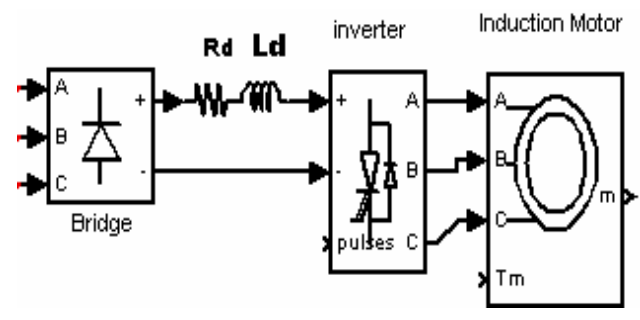

Fig. 1: Current source inverter induction motor drive
Dynamic performance and stability problems at light load and in high-frequency conditions ${ }^{[5]}$ Fig. 1

Various simplified methods of studying the dynamics of IM have been investigated and used in power system transients, stability studies and drive systems control ${ }^{[6-9]}$. All these models are developed for VSI-IM drives. In this study, reduced order dynamic models of a CSI-IM drive have been developed. The dynamics of a CSI-IM drive are described by a set of first order nonlinear differential equations. To linarite these equations, a small signal perturbation around steady state operating point can be used ${ }^{[10,11]}$, or the electromagnetic transient of the drive system can be studied assuming a constant rotor speed, i.e., large inertia ${ }^{[12,13]}$. In the current study, three reduced order models are developed for a CSIIM drive.

A detailed fifth order model is obtained by selecting a specific reference frame, which is stationary with respect to the stator voltage vector and one of its axes is always aligned with $\mathrm{it}^{[14]}$. Based on this model, a stator-transient fourth order model is also derived by neglecting the stator transients ${ }^{[10,12]}$. Another fourth order, stator-equation model, is derived by neglecting the stator equations ${ }^{[11,15]}$. The transient response of all models resulting from the variations of the input signals and disturbances are studied and compared.

Corresponding Author: Ibrahim K. Al-Abbas Department of Mechatronics Engineering, Faculty of Engineering Technology, Al-Balqa Applied University, Amman, Jordan 
Am. J. Engg. \& Applied Sci., 2 (1): 39-43, 2009

\section{MATERIALS AND METHODS}

Inverter-machine modeling: A drive system with the following parameters was used:

$\begin{array}{ll}\text { Nameplate motor data } & \\ \text { Output } & 7.5 \mathrm{KW} \\ \text { Voltage } & 220 \mathrm{~V} \\ \text { Primary current } & 27.3 \mathrm{~A} \\ \text { Frequency } & 60 \mathrm{~Hz} \\ \text { Number of poles } & 6 \\ \text { Inertia } & 1.5 \mathrm{~kg} \cdot \mathrm{m}^{2} \\ \text { Motor parameters } & \\ \mathrm{r}_{\mathrm{s}} & 0.1695^{\prime} \Omega \\ \mathrm{r}_{\mathrm{r}} & 0.2445 \Omega \\ \mathrm{L}_{\mathrm{s}} & 32.5 \mathrm{mH} \\ \mathrm{L}_{\mathrm{r}} & 32.96 \mathrm{mH} \\ \mathrm{M} & 31.59 \mathrm{mH} \\ \text { Filter parameters } & \\ \mathrm{R}_{\mathrm{d}} & 0.335 \Omega \\ \mathrm{L}_{\mathrm{d}} & 324 \mathrm{mH}\end{array}$

For a large dc link, the equation of the dc link circuit may be written as:

$$
\mathrm{V}_{\mathrm{R}}=\mathrm{L}_{\mathrm{d}} \frac{\mathrm{II}_{\mathrm{d}}}{\mathrm{dt}}+\mathrm{R}_{\mathrm{d}} \mathrm{I}_{\mathrm{d}}+\mathrm{V}_{\mathrm{D}}
$$

The equations of the induction machine, expressed in the arbitrary reference frame rotating with velocity $\omega$ for the stator's circuit, are as follows:

$$
\begin{aligned}
& \frac{\mathrm{d}}{\mathrm{dt}}\left[\begin{array}{c}
\mathrm{i}_{\mathrm{sd}} \\
\mathrm{i}_{\mathrm{sq}}
\end{array}\right]=\frac{\omega_{0}}{\mathrm{D}}\left[\begin{array}{cc}
\mathrm{r}_{\mathrm{s}} \mathrm{X}_{\mathrm{r}} & -\left(\omega \mathrm{D}+\omega_{\mathrm{r}} \mathrm{X}_{\mathrm{m}}{ }^{2}\right) \\
\left(\omega \mathrm{D}+\omega_{\mathrm{R}} \mathrm{X}_{\mathrm{M}}^{2}\right) & \mathrm{r}_{\mathrm{s}} \mathrm{X}_{\mathrm{r}}
\end{array}\right. \\
& \left.\begin{array}{cc}
-r_{\mathrm{r}} \mathrm{X}_{\mathrm{m}} & -\omega_{\mathrm{r}} \mathrm{X}_{\mathrm{r}} \mathrm{X}_{\mathrm{m}} \\
\omega_{\mathrm{r}} \mathrm{X}_{\mathrm{r}} \mathrm{X}_{\mathrm{m}} & -\mathrm{r}_{\mathrm{r}} \mathrm{X}_{\mathrm{m}}
\end{array}\right]\left[\begin{array}{c}
i_{\mathrm{sd}} \\
i_{\mathrm{sq}}
\end{array}\right]+ \\
& \frac{\omega_{0}}{D}\left[\begin{array}{cccc}
-X_{r} & 0 & X_{m} & 0 \\
0 & -X_{r} & 0 & X_{m}
\end{array}\right]\left[\begin{array}{l}
u_{s d} \\
u_{s q}
\end{array}\right]
\end{aligned}
$$

(2)

And for the rotor's circuit, the equations are:

$$
\begin{aligned}
& \frac{\mathrm{d}}{\mathrm{dt}}\left[\begin{array}{c}
\mathrm{i}_{\mathrm{rd}} \\
\mathrm{i}_{\mathrm{rd}}
\end{array}\right]=\frac{\omega_{0}}{\mathrm{D}}\left[\begin{array}{cc}
-\mathrm{r}_{\mathrm{s}} \mathrm{X}_{\mathrm{m}} & \omega_{\mathrm{r}} \mathrm{X}_{\mathrm{s}} \mathrm{X}_{\mathrm{m}} \\
-\omega_{\mathrm{r}} X_{\mathrm{s}} X_{\mathrm{m}} & \mathrm{r}_{\mathrm{s}} \mathrm{X}_{\mathrm{m}}
\end{array}\right. \\
& \left.\begin{array}{cc}
-r_{r} X_{s} & -\left(\omega D-\omega_{r} X_{s} X_{r}\right) \\
\left(\omega D-\omega_{r} X_{s} X_{r}\right) & -r_{r} X_{m}
\end{array}\right]\left[\begin{array}{l}
i_{r d} \\
i_{r q}
\end{array}\right]+ \\
& \frac{\omega_{0}}{D}\left[\begin{array}{cccc}
X_{\mathrm{m}} & 0 & -\mathrm{X}_{\mathrm{s}} & 0 \\
0 & \mathrm{X}_{\mathrm{m}} & 0 & -\mathrm{X}_{\mathrm{s}}
\end{array}\right]\left[\begin{array}{l}
\mathrm{u}_{\mathrm{rd}} \\
\mathrm{u}_{\mathrm{rq}}
\end{array}\right]
\end{aligned}
$$

The developed electromagnetic torque is defined by the following equation:

$$
\mathrm{T}_{\mathrm{e}}=1.5 \mathrm{PX} \mathrm{m}_{\mathrm{m}}\left(\mathrm{i}_{\mathrm{sq}} \mathrm{i}_{\mathrm{rd}}-\mathrm{i}_{\mathrm{sd}} \mathrm{i}_{\mathrm{rq}}\right)
$$
is:

Finally, the motion equation of the drive system

$$
\mathrm{T}_{\mathrm{e}}-\mathrm{T}_{1}=2 \mathrm{H} \frac{\mathrm{d} \omega_{\mathrm{r}}}{\mathrm{dt}}
$$

\section{RESULTS}

Assessment of the reduced order models: Before assessing the accuracy of the reduced order models in predicting the dynamic behavior of the drive system, it is necessary to investigate the dynamic of the IM when it is supplied from a CSI as well as from a VSI. As a case of study, a $7.5 \mathrm{~kW}$ induction motor drive is considered. The steady sate operating point for all cases is determined by applying a rated load torque to the machine. The drive systems are simulated using MATLAB/SIMULINK. Figure 2 shows the time response of the $\mathrm{dc}$ current, rotor speed and electromagnetic torque for a step decrease of the supply voltage from Fig. 2, it is evident that the output variables of the current fed drive exhibit more oscillation than those of the voltage fed drive, especially the rotor speed. Moreover, there is a step change in the dc current and electromagnetic torque in the starting point, which is the case in actual CSIIM drives.

Reduced order modeling: The dynamic model of the CSI-IM is of a six-order and can be solved only by using a computer simulation to investigate the system's outputs. To simplify the simulation procedure and determine the analytical models, the following reduced order models will be developed. To compare the performance and accuracy of the reduced order models, the deviation of output variables of the drive system due to a $10 \%$ step decrease of the supply voltage and due to a $10 \%$ step decrease of the load torque are obtained

Specific reference frame model: When the induction machine equations are expressed in a synchronously rotating frame of reference with machine currents and when the harmonics of the line currents are neglected, thus $\mathrm{i}_{\mathrm{qs}}=\mathrm{I}_{\mathrm{d}}, \mathrm{i}_{\mathrm{ds}}=0$ and $\mathrm{V}_{\mathrm{d}}=\mathrm{v}_{\mathrm{qs}}$, only the direct stator equation is used in modeling, while the quadrature stator equation is omitted. 
Am. J. Engg. \& Applied Sci., 2 (1): 39-43, 2009

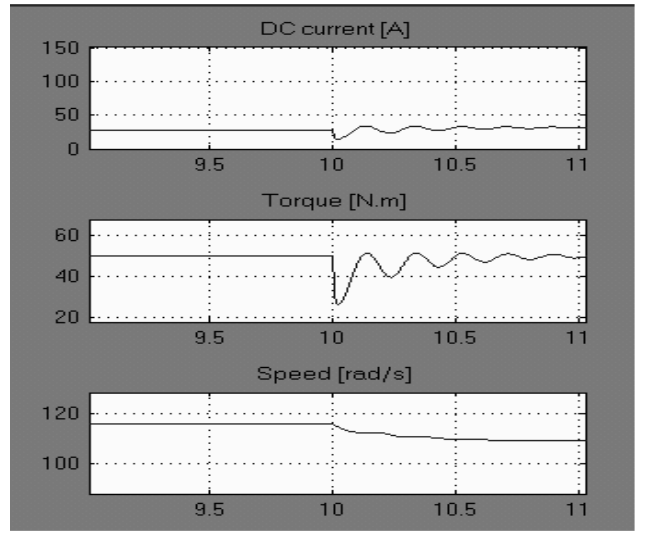

Fig. 2a: Voltage fed drive: Time response to a $10 \%$ step decrease of the supply voltage

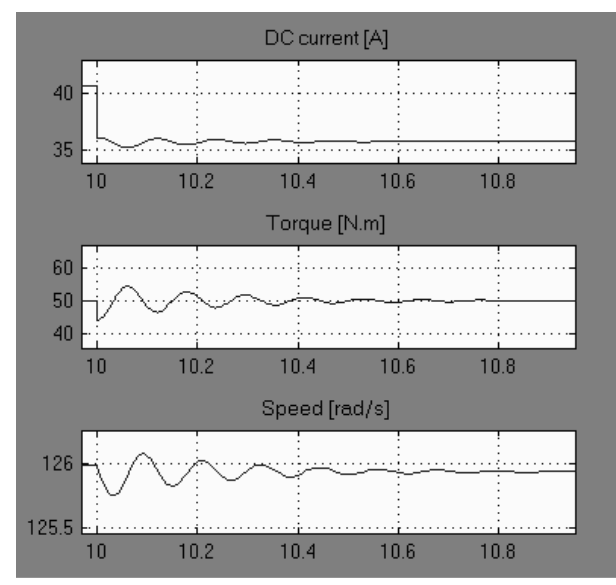

Fig. 2b: Current fed drive: Time response to a $10 \%$ step decrease of the supply voltage

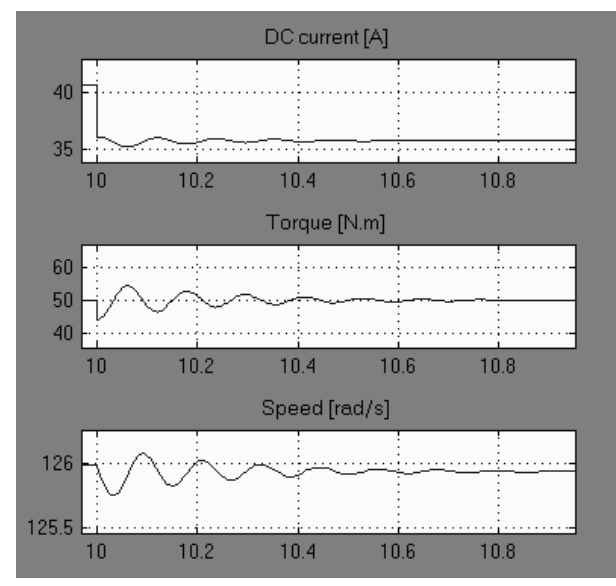

Fig. 3a: Detailed model: Time response to a $10 \%$ step increase of the supply voltage.

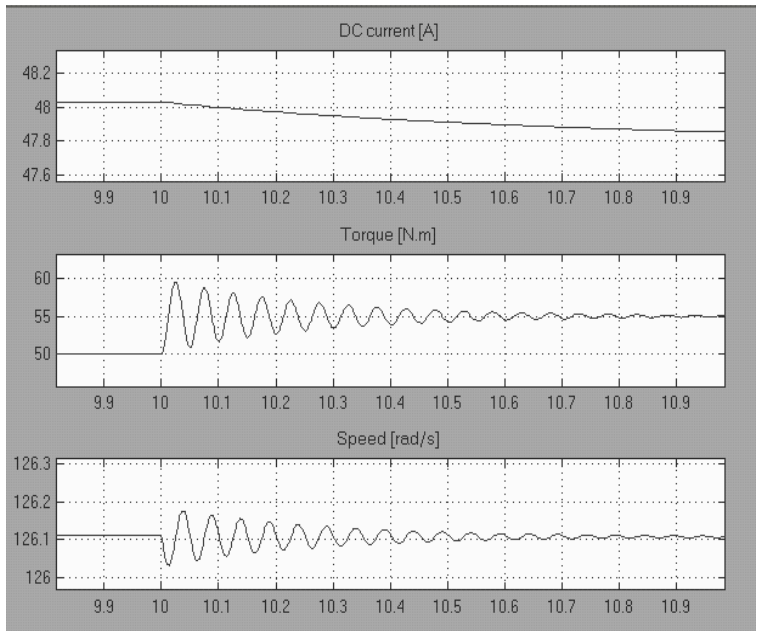

Fig. 3b: Detailed model: Time response to a $10 \%$ step increase of the load torque

Selecting the reference frame reduced the order of the mathematical model by one. But, this model is nonlinear because of the angular speed in the rotor equations and the transient conditions are unknown. The time response of this model is shown in Fig.3 for step change in supply voltage and step change in the load.

Neglecting stator transients: This type of reduction to mathematical models of induction machines is widely used due to its computational efficiency, satisfactory accuracy and convenient form of equations. It is derived by setting equal to zero the derivatives of the stator currents in (2), or by setting to zero the derivatives of the stator fluxes, if these are used as state variables in mathematical modeling. This approach reduces the order of the original model of the drive system by two. The dynamic response for this case is depicted on Fig. 4

Neglecting stator equations: For normal operation of current source inverters, an internal control loop for the machine stator currents is usually used. For such a case, we can assume that the machine is supplied from an ideal current source with sinusoidal waves. In addition, we can simplify the dynamic model of the drive system by neglecting the stator's equation of the induction machine. The order of the dynamic model is reduced by two and it is simpler than that one obtained by neglecting the stator transients. The outputs of the drive are presented by Fig. 5 . 
Am. J. Engg. \& Applied Sci., 2 (1): 39-43, 2009

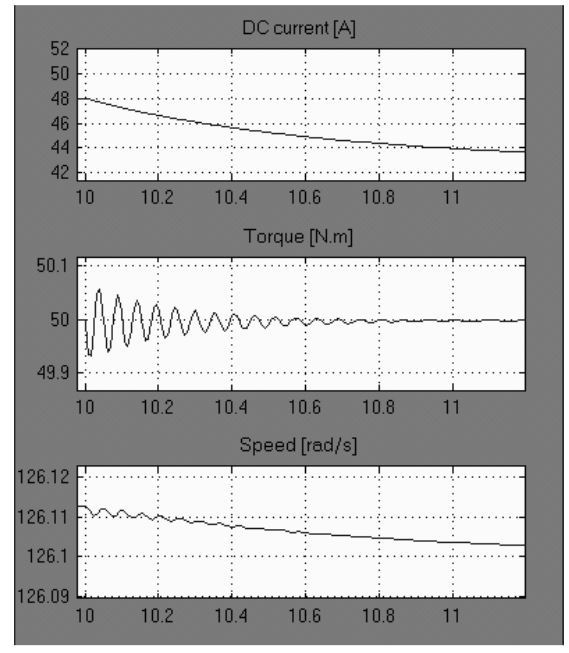

Fig. 4a:Stator transient model: Time response to a $10 \%$ step decrease of supply voltage

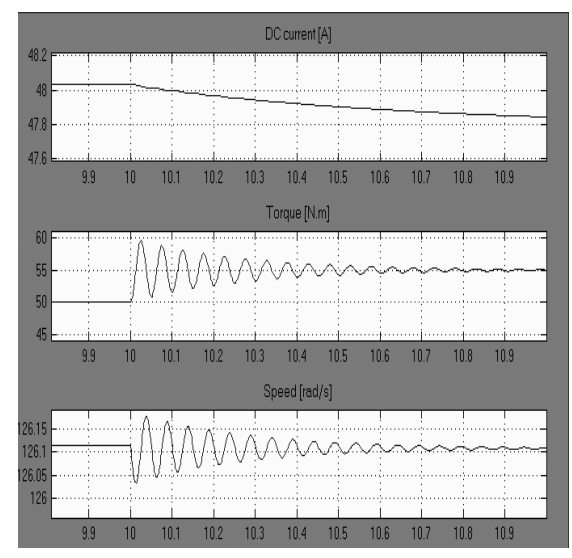

Fig. 4b: Stator transient model: Time response to a $10 \%$ step increase of load torque

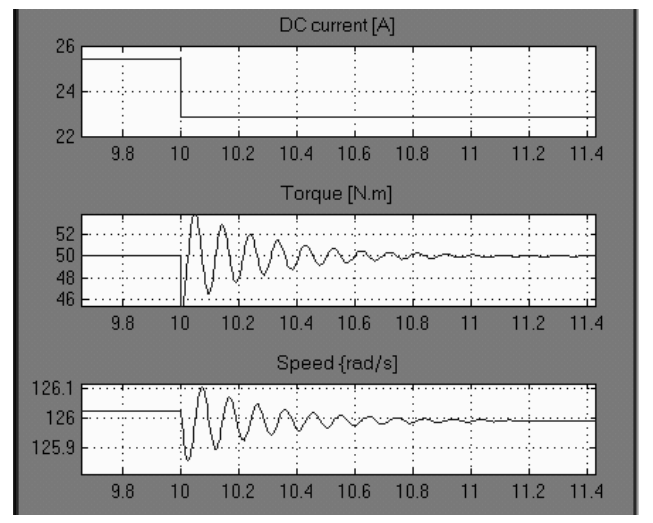

Fig. 5a: Stator equations model: Response to a $10 \%$ step decrease of supply voltage

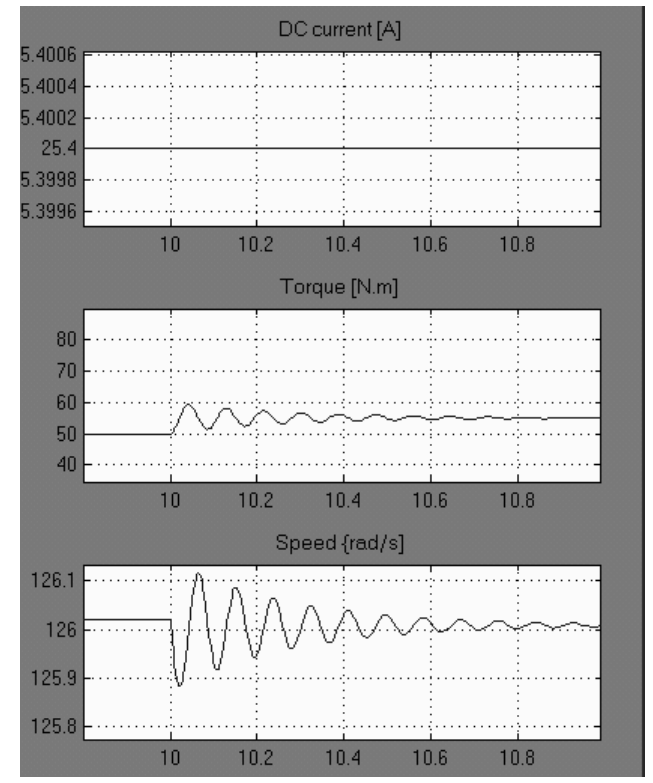

Fig. 5b: Stator equation model: Time response to a $10 \%$ step increase of load torque

\section{DISCUSSION}

The dynamics of the reduced order models are compared with the response of a full order model shown in Fig.2a. The obtained detailed model and full order model have the same time response. For that the detailed model will be considered as a reference when analyzing the dynamics of reduced models due a step change in the load torque.

\section{Dynamic response to a step decrease of the supply} voltage: As expected, there is a decrease in the rotor speed and an increase in the dc current. The electromagnetic torque has oscillations with the same frequency in the interval immediately following the step change of the supply voltage. The torque response of the stator transient model differs from the other two responses and it has a smaller amount magnitude. When the transients of the rotor speed were analyzed, it was found that there is a slight deviation from the initial value and the transient model has an over damped shape. The error of the detailed model and the stator equation model is less than $5 \%$, while the response of the transient model is not acceptable.

Dynamic response to a step increase of the load torque:. The results indicated that there is a good agreement among these curves during the transient state and throughout the steady state. the deviations 
in performance specifications, such a max overshoot and a settling time are not more than 5\%.

\section{ACKNOWLEDGEMENT}

This study is done during sabbatical leave this sabbatical would not have been possible without the encouragement and support of al-Balqa university and Hashemite university.

\section{REFERENCES}

1. Salo, M., Tuusa, H., 2005. Vector-controlled PMW current source inverter fed induction motor drive with a new stator current control method. IEEE transactions ion industrial electronics ,52(2) :523-531. DOI 10.1109/TIE.2005.844243

2. Toliyat, H. A. and T. A. Lipo, 1995. Transient Analysis of cage induction machines under stator, rotor bar and end ring faults, IEEE Trans. Energy Conversion, 10(2):41-247. DOI $: 1109 / 60.391888$

3. Salo, M. and H. TTuusa.2005. A vector controlled current-source PMW rectifier with a novel current damping method. IEEE Trans. Power Elect. 15(3): 464-470. DOI $10.1109 / 63.844506$

4. Muller, S. Deicke, M. De Doncker, R.W., 2002.Doubly Fed Induction Generator for Wind Turbine. IEEE Ind. Appl. Magazine, 8(3): 26 33 DOI: $10.1109 / 2943.999610$

5. Boldea I. Nasar S.A, 2006, Electric drives.CRC press, 2ed edition. Taylor and Francis Group, Boca Raton, ISBN 0-8493-4220- URL: http://www.accessmylibrary.com/coms2/summar y_0286-31189666_ITM

6. Wei Qiao Wei Zhou Aller, J.M. Harley, R.G. , Wind Speed Estimation Based Sensorless Output Maximization Control for a Wind Turbine Driving a DFIG, IEEE Trans. Power Elect.,23(3): 1156-1169, DOI :10.1109/TPEL.2008.921185 Ong, C.H, 1997.
7. Dynamic Simulation of ElectricMachinery Using Matlab/ Simulink, second edition, Upper Saddle River, Prentice Hall.625pages. ISBN: 01 372337855.URL:http://www.bookpool.com/sm/ 0137237855

8. Harnefors, L.; Nee, H.-P, 1998.Model-Based Current Control of AC Machines Using the Internal Model Control Method, IEEE Trans. Ind. Appl., 34(1): 133-141.

DOI: $1109 / 28.658735$.

9. Tsuji, M., Shuo Chen, Izumi, K. Yamada, E. A sensorless vector control system for induction motors using q-axis flux with stator resistance identification, IEEE transactions ion industrial electronics, 48(1):185194,DOI:10.1109/41.904579

10. Wasynczuk, O., Y.M. Diao and P.C. Krause, 1985. Theory and comparison of reduced order models of induction machines. IEEE Trans. Pow. Appl. Syst., PAS-104(3) : 598-606. DOI: 10.1109/TPAS.1985.318977

11. D. Sudhoff, D. Aliprantis, B.T. Kuhn, P. L. Chapman, 2002. An Advanced induction machine model for Predicting Inverter-machine Interaction, IEEE Transactions on Energy Conversion, 17(2): 203-210, DOI: 10.1109/TEC.2002.1009469

12. Papathanasiou, S.A. and M. Papadopoulos, 2000. Simplified d-q dynamic models of the slip energy recovery drive. ETEP, 10: 361-367.URL: http://users.ntua.gr/stpapath/study_1.7.pdf

13. Leonhard, W, 2001.Controlof Electrical Drives.Springer; 3rd ed. ISBN-10:3540418202. URL:http://www.amazon.com/ControlElectrical-Drives-WernerLeonhard/dp/3540418202

14. Bose B. K., 2001.Modern Power Electronics and AC Drives, Prentice Hall. 1st ed., ISBN10:0130167436,ISBN-13: 9780130167439.

URL:http://www.pearsonhighered.com/academic/ product/0,3110,0130167436,00.html

15. Xiaojun Geng Hammer, J. 2005 ,Input/output control of asynchronous sequential machines. IEEE Transactions on automatic control, 50(12) :1965-1970. Digital Object Identifier: 10.1109/TAC.2005.860293 